\title{
Mindfulness begins with ourselves
}

\section{Opinion}

I was traveling recently with my kids, and while leaving a store, an interesting question popped up from my older 14-year old son. "Mom, why is people so rude? I have hold the door for three folks, and nobody turned to say thank you." That was a tough question; I wanted to combat his sense of frustration, and at the same time instill hope in his values and character; the catch was how to do this without down talking about others, otherwise, where would that modeling be? So, we ended reflecting on individual's responsibility in life and how each other contribute to a better world with small "insignificant" actions that make you feel good about yourself.

This brings me to mindfulness. In today's academic medicine, mindfulness has taken relevance because of its role in managing stress, and increasing awareness about our own practices that may lead to a non-healthy life. Working in the healthcare environment can be very stressful and professional expectations about being perfectly suited for anything that comes along is very high. There is always time to pay attention to others, but never to ourselves. That is kind of a wrong way of practicing "care". Instead, the regular practice of mindfulness promotes continuous awareness of our thoughts, feelings, and surrounding environment. Through this practice, we not only learn to discover how our body responds to stimuli, but we learn to appreciate those responses, understand those reactions, and make something of it. An individual who is aware of his/herself is awake to life, and through this awareness there is constant reflection and growth. As a physician myself, I have experienced living in automatic pilot more than once, expecting everything to work out perfect, and being very critical of myself when the results are contrary to my goals. On other occasions, time for reflection is omitted just because of the pain associated to the process. But in mindfulness, there is no good or bad reactions to the stimuli perceived, to the thoughts that invade us, there is just conscious awareness of "what happened, of what is felt"; and because of that enlightening moment, there is non-judgmental reflection that can provoke thoughts that may lead to growth, acceptance, and peace of mind. For those who live in elevated levels of stress, mindfulness may help individuals discover their bodily reactions when stress persists. This learning can be powerful.

In the healthcare world we are learning to discover the role of mindfulness and how we can apply it to ourselves and to our patients. We are learning to accept our environment with gratitude and patience. But this discovery does not occur by chance; there is a systemic experience in mindfulness which includes: observing ourselves (feelings, senses, emotions), describing the emotion (label the sensation), acting with awareness (paying attention to own actions), non-judging of the inner experience (refrain from judging ourselves), and non-reactivity to the inner experience (allowing feelings and thoughts to present and leave our attention without holding to them). ${ }^{1,2}$ And even though it could seem that this systematic exercise can limit to managing psychological symptoms, I see it being applied to any aspect of life.
Volume II Issue 2 - 2018

\author{
Maricarmen Cruz-Jimenez \\ Physical Medicine and Rehabilitation, USA
}

Correspondence: Maricarmen Cruz-Jimenez, Physical Medicine and Rehabilitation,VA Caribbean,healthcare System, San Juan PR, USA, Email Maricarmen.Cruz-Jimenez@va.gov

Received: February 21, 2018 | Published: March 12, 2018

For a teenager, ungratefulness can provoke both anger and indifference, eventually teaching the wrong response to a stimulus. My kid was right; people went through that door without noticing that a young man was courteously holding the door for them. And that moment had two faces to a coin: the walker who was unaware of the environment, very focused on him/her, not paying attention to what was going on; there was no appreciation, no compassion, and no connection. The other face of the coin was a mindful kid totally aware of the circumstance, full of emotions, expecting to connect to others, and reflecting on how to feel toward the situation, how to respond to his environment. So how frequently do we realize the good deeds others have towards us? Do we realize how disconnected we are to world? But most sadly, are we so disconnected to ourselves that we don't even notice this is happening?

Being on the side of the coin that notices the indifference of others can provoke grief and justifying ideas, but mindful reflection can teach us about being patient with our own feelings and other's behaviors. The journey may take time, but the beauty will manifest when compassion turns into act of kindness towards ourselves and our neighbors. As I told my kid, we are individually responsible for our decided actions and for improving this world, mindful acts begin with ourselves.

\section{Acknowledgment \\ None}

\section{Conflict of interest}

Author declares there is no conflict of interest towards this manuscript.

\section{References}

1. Baer RA, Smith GT, Allen KB. Assessment of Mindfulness by Self Report: The Kentucky Inventory of Mindfulness Skills. Assessments. 2004;11(3):191-206.

2. Carmody J, Baer RA. Relationships between mindfulness practice and levels of mindfulness, medical and psychological symptoms and wellbeing in a mindfulness-based stress reduction program. $J$ Behav Med. 2008;31(1):23-33. 